\title{
Revisitando o desastre de Bhopal: os tempos da violência e as latitudes da memória
}

BRUNO SENA MARTINS"

\section{Resumo}

Na madrugada de 3 de dezembro de 1984, um acidente numa fábrica da filial indiana da empresa estadunidense Union Carbide Corporation (UCC) viria a desencadear o maior desastre industrial da história: o desastre de Bhopal. Neste texto, a partir de um trabalho etnográfico recente, propõe-se um encontro, mais de 30 anos depois, com as vozes daqueles cujas vidas foram afetadas pelo desastre de Bhopal. Esta abordagem pretende convocar leituras sobre o tempo, a violência e as demarcações de humanidade que definem a memória social. Em particular, pretende-se questionar os processos pelos quais algumas vidas são desproporcionadamente expostas à violência e fracassam em receber justa compensação, bem como os itinerários pelos quais alguns sofrimentos são tendencialmente elididos da memória social do Ocidente. Finalmente, analisa-se a forma como a vulnerabilidade biográfica e corpórea, imposta pelo desastre, criou espaços de enunciação e narrativas de resistência. ${ }^{1}$

Palavras-chave: Desastre de Bhopal. Epistemologias do Sul. Violência Lenta. Índia. Memória Social.

\footnotetext{
${ }^{*}$ Centro de Estudos Sociais (CES) da Universidade de Coimbra (Portugal)

${ }^{1}$ Artigo elaborado no âmbito do projeto de pesquisa "ALICE - Espelhos Estranhos, Lições Imprevistas: Definindo para a Europa um novo modo de partilhar as experiências do Mundo", financiado pelo 7.․ Programa-Quadro da União Europeia (FP/2007-2013)/ERC Grant Agreement no. 269807.
} 


\title{
Revisiting the Bhopal disaster: times of violence and latitudes of memory
}

\begin{abstract}
On the night of 2-3 December 1984, an accident in the Indian subsidiary of the US company Union Carbide Corporation (UCC), located in the city of Bhopal, would unleash the world's worst industrial disaster: the Bhopal disaster. In this paper, based on a recent ethnographic fieldwork, more than 30 years later, an encounter with the voices of those whose lives have been affected by the Bhopal disaster This approach intends to convene readings over time, violence and demarcations of humanity that define the social memory. In particular, the processes by which some lives are disproportionately exposed to violence and the paths through which some forms of suffering tend to be erased from the social memory of the West are questioned. Finally, the spaces of enunciation and resistance created within the biographical and corporeal vulnerabilities imposed by the disaster will be addressed.
\end{abstract}

Keywords: Bhopal Disaster. Epistemologies of the South. Slow Violence. India. Social Memory. 


\section{Introdução}

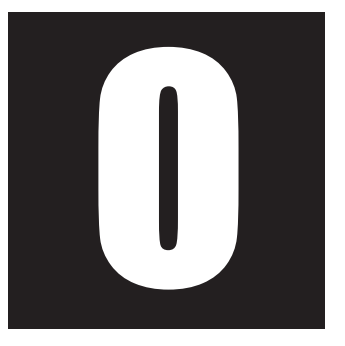

acidente na fábrica da Union Carbide India Limited (UCIL), ${ }^{2}$ filial da empresa estadunidense Union Carbide Corporation (UCC), instalada em Bhopal, na Índia, viria a desencadear o maior desastre ${ }^{3}$ industrial da história. As estimativas fazem supor que milhares de pessoas tenham morrido entre aquela noite e as semanas seguintes ao acidente, vinte e cinco mil, nos anos subsequentes, e que existam atualmente mais de cem mil pessoas com importantes sequelas permanentes (BMA \& BGIA, 2012). Perante a dimensão do acidente e a magnitude das suas consequências, não deixa de ser surpreendente a escassa representação que o desastre de Bhopal detém na memória do Norte global. Esta perplexidade, creio, é indicativa dos processos radicalmente diferenciais pelos quais se constitui a ideia de humano e dos sofrimentos merecedores de luto e revolta. Tal reflexão remete, por um lado, para uma gramática ampla das distinções histórica, cultural e politicamente engendradas, através das quais as diferenças no valor da vida foram sendo constituídas e significadas. Conforme refere Judith Butler,

O humano é entendido diferentemente dependendo da sua raça, a legibilidade da sua raça, do seu sexo, a verificabilidade preceptiva desse sexo, da sua etnicidade, a compreensão categorial dessa etnicidade (Butler, 2004a, p. 2).

\footnotetext{
${ }^{2}$ A UCIL foi estabelecida em 1934. Esta filial, embora contando com participação de investidores indianos a partir de 1956, incluindo do próprio Estado indiano, manteve-se sempre na propriedade maioritária da UCC.

${ }^{3}$ Para uma análise de algumas das mais importantes aceções que o conceito de desastre tem adquirido na teoria social, ver Oliver-Smith (1996).
} 
Esta denúncia, a partir da qual a hierarquia na definição do humano é exposta, em favor da ideia de que há sujeitos e grupos que têm de lutar pelo direito a serem vistos como humanos (Baxi, 1986; Fanon, 2004), não só visibiliza as desigualdades no estatuto ontológico produzidas em todas as sociedades, como exprime as assimetrias constituídas a nível planetário:

As vidas são defendidas e mantidas diferencialmente, e existem formas radicalmente diferentes através das quais a vulnerabilidade é distribuída através do globo. Algumas vidas serão bastante protegidas, e a revogação das suas alegações à santidade será suficiente para mobilizar as forças da guerra. Outras vidas não encontrarão uma defesa tão rápida e furiosa e nem sequer se qualificarão como vidas "passíveis de luto" ${ }^{\prime \prime}$ (Butler, 2004b, p. 32).

Desde a implantação da fábrica de Bhopal, em 1969, até à negligência que continua afetando as vítimas do desastre nos dias de hoje, compõe-se uma trama de eventos que, como procurarei mostrar, dá pujante testemunho de um nexo colonial-capitalista cujo poder se revela na desqualificação do valor da vida dos sobreviventes de Bhopal.

No diálogo que procuro desenvolver neste texto, os sobreviventes do desastre de Bhopal e as suas experiências requerem um esforço analítico de superação de duas formas de silenciamento. Em primeiro lugar, o silenciamento que resulta das hierarquias que naturalizam a subalternidade das vivências e das reflexões ontológicas dos sobreviventes, aí se definindo os termos de uma voz sumamente silenciada. Em segundo lugar, procuro superar o silenciamento que resulta da dificuldade em apreender um desastre industrial numa temporalidade longa; refiro-me ao modo como as décadas que se seguiram ao desastre dão conta de uma "violência lenta" (Nixon, 2011), uma violência que continuou ocupando os cotidianos daqueles que sobreviveram à madrugada de 3 de dezembro de 1984.

\footnotetext{
$\overline{{ }^{4} \text { No original, grievable. }}$
} 


\section{Nota metodológica}

O presente texto resulta de um trabalho etnográfico que realizei entre dezembro de 2013 e fevereiro de 2014, na cidade de Bhopal, em estreita articulação com a organização não-governamental (ONG) Sambhavna Trust (ST), cuja clínica, situada nas imediações da fábrica onde se desencadeou o desastre, até hoje presta cuidados de saúde aos sobreviventes de Bhopal. Durante o período que vivi em Bhopal, fiquei a residir na clínica da ST, onde, de segunda a sábado, 180 sobreviventes recebem cuidados médicos (são atendidos por profissionais de medicina convencional e de medicina ayurveda). Fui acolhido na ST como um académico interessado em fazer uma pesquisa sobre o desastre de Bhopal, tendo-me sido providenciadas as mesmas condições oferecidas aos voluntários de todo o mundo que queiram participar das atividades da organização, bem como o apoio de um assistente de pesquisa para as minhas itinerâncias fora da clínica. Através dessa situação de proximidade privilegiada com as sequelas do desastre - acordava todos os dias com o som do altifalante que chamava os utentes para os consultórios -, pude recolher o tempo longo em que se inscrevem as sequelas do desastre Bhopal: o continuado sofrimento inscrito nos corpos; a luta por compensações e cuidados de saúde; a exposição diária aos efeitos da contaminação; e o impacto das malformações congénitas das novas gerações. Durante a estadia em Bhopal, visitei as casas das comunidades situadas nas circunscrições mais afetadas pelo desastre, pude estabelecer diálogos e entrevistas com sobreviventes, ativistas, pessoal médico e jornalistas. Além das múltiplas conversas que a vivência quotidiana permitiu, realizei um total de 35 entrevistas mais formais, consistindo estas de um guião semiestruturado de perguntas, normalmente cruzado com a recolha de histórias de vida dos interlocutores (as entrevistas foram gravadas em áudio), sempre com o consentimento informado dos entrevistados. Tive o apoio de um intérprete nas entrevistas, sempre que a 
barreira entre o hindi e o inglês não pôde ser superada sem esse expediente. Procedi ainda à análise documental na biblioteca da ST, onde se situa o mais completo arquivo documental e bibliográfico sobre o desastre de Bhopal e sobre as lutas que se lhe seguiram.

Para um pesquisador português, nascido 6 anos antes do desastre, com um percurso pessoal que a fortuna e o privilégio colocaram a salvo das asperezas da vida, aceder à realidade dos sobreviventes de Bhopal trouxe consigo o desafio de complexas travessias: linguísticas, geográficas, culturais, memorativas e subjetivas.

As mais de três décadas que nos separam do desastre de Bhopal colocam ao centro o desafio para uma apreensão de um tempo distendido, em que as implicações do desastre foram incessantemente vividas pelos sobreviventes de Bhopal. Cabe assim

perceber como é que a dispersão temporal da violência lenta condiciona o modo como aprendemos e respondemos a uma variedade de flagelos sociais [...]. Um desafio importante é representacional: como conceber histórias, imagens e símbolos cativantes adequados à violência disseminada mas elusiva de efeitos deferidos (Nixon, 2011, p. 3).

Num trabalho em que avulta um presente ainda marcado pela madrugada de 3 de dezembro de 1984 - "aquela noite", como todos a referem em Bhopal, a noite da perda de familiares, vizinhos e outras pessoas queridas, e que em tantos instaurou uma vida de dores físicas, doenças e memórias traumáticas -, tomei contato com a necessidade de merguIhar nos mundos locais da experiência, conforme Arthur Kleinman refere: Para uma etnografia da experiência, o desafio é descrever a elaboração processual da exposição, da resistência, do suporte da dor (ou perda ou outra tribulação) no fluxo vital dos engajamentos intersubjetivos num mundo local particular (Kleinman, 1992, p. 191). 
Kleinman defende que, se por um lado as leituras eminentemente biomédicas do sofrimento fracassam em aceder às questões teleológicas e existenciais que este coloca, por seu lado, as interpretações mais "culturalistas" tendem a fechar-se numa leitura estritamente intelectualista do sofrimento. Isso, sobretudo pelo fato de, na esteira de Max Weber, se ter colocado no centro das abordagens do sofrimento a produção de discursos que fazem supor respostas límpidas no seio de narrativas coerentes da existência (Kleinman, 1992, p. 189-190). A ideia de que o sofrimento constitui um itinerário a que os sujeitos procuram resistir elaborando perspectivas de sentido, culturalmente informadas pelos mundos locais particulares, que necessariamente convivem com o caos, com o indizível e destituído de sentido, concilia-nos com uma leitura em que o corpo, os valores culturais e a autorreflexividade, constituída nos vagares da biografia, se podem encontrar, sem contradição ou agonismo.

Nesta perspectiva, ensaiei uma pesquisa que se pode entrever em duas linhas distintas e complementares. Por um lado, perseguir o sentido aposto pelos sujeitos a eventos desestruturantes que, às vezes, de tão inscritos na incomunicabilidade de uma subjetividade ferida, lutam para encontrar lugar na linguagem. Deste modo, aproximo-me do que Boaventura de Sousa Santos designa por "sociologia das ausências", cujo objetivo é "transformar objectos impossíveis em objectos possíveis e com base neles transformar as ausências em presenças" (Santos, 2002, p. 246). Por outro lado, cabe perceber como da luta contra a tribulação emergem "novas linguagens", narrativas de resistência que, entre a subjetividade ferida e uma insurgência partilhada, elaboram propostas de justiça e transformação social. Nesta perspectiva, inscrevo-me numa "sociologia das emergências", cujo objetivo é "conhecer melhor as condições de possibilidade da esperança definindo princípios de acção que promovam a realização dessas condições" (Santos, 2002, p. 256). 


\section{"Aquela noite": história e histórias}

Bhopal é a capital do Estado de Madhya Pradesh (literalmente, a província do meio), e está situada no Centro da Índia, contando, segundo dados dos Censos de 2011, com um total 1798218 habitantes. A moderna cidade de Bhopal foi fundada no século XVIII, por Dost Mohammad Khan, um soldado afegão, e viria a tornar-se um principado semiautónomo do império mogol (organização política cujo líder se designava nawab, no caso de ser homem, ou begum no caso de ser mulher). Com a colonização britânica, o Estado de Madhya Pradesh adquiriu o estatuto de Princely State, na prática, tornou-se um protetorado governado por monarcas locais, descendentes do império mogol, através de uma aliança (subsidiary aliance) que implicava a subscrição das condições impostas pelo poder colonial britânico. Curiosamente, Madhya Pradesh foi governado por 4 mulheres (Beguns) de 1819 a 1926, e o principado só se desfez já em 1949, passando a integrar a União Indiana, já após a independência da Índia, ocorrida em 1947. Esta situação fez com que o Estado de Madhya Pradesh fosse o segundo maior Estado indiano a ser governado por monarcas muçulmanos até ao século XX, o que explica que, num país maioritariamente hindu, o distrito de Bhopal tenha, ainda hoje, uma significativa percentagem de população muçulmana (em 2001, $73,05 \%$ da população era hindu e 22,8\% muçulmana, quando na Índia era de $80,5 \%$ e $13,4 \%$, respectivamente ${ }^{5}$ ).

Foi ainda sob o governo das Beguns que o Estado de Madhya Pradesh iniciou o estabelecimento de ligações ferroviárias com o resto da Índia, elemento que, associado a uma situação geográfica central, contribuiu para que Bhopal se viesse a tornar num importante entroncamento ferroviário ao longo da primeira metade do século XX. Quando os diri-

\footnotetext{
${ }^{5}$ Conforme <http://www.icssr.org/Baseline\%20Survey\%20of\%20Bhopal\%20District.pdf>.
} 
gentes da Índia independente decidiram apostar no crescimento do setor industrial doméstico, as ligações ferroviárias privilegiadas com o resto do território foram cruciais para que Bhopal se tornasse um lugar adequado para o estabelecimento de indústrias. A estes fatores acresceram os incentivos fiscais resultantes do fato de o Estado de Madhya Pradesh ter sido classificado como de baixo desenvolvimento.

No entanto, a instalação de uma fábrica da UCIL na cidade de Bhopal no ano de 1969 não é separável das transformações impostas pelo que então se designou de "revolução verde". Na primeira metade do século XX, marcadamente na década de 1920, a Índia viveu uma marcada situação de fome e precariedade alimentar. Perante igual cenário nos anos 1950, o governo indiano lançou a "revolução verde", um programa alargado que visava a autossuficiência alimentar através da introdução de tecnologias agrónomas. As medidas adotadas incluíam o uso de maquinaria na agricultura, alargamento das estruturas de irrigação, introdução de sementes de alta produtividade e - dado crucial para o tema em análise - o aumento exponencial do uso de pesticidas na produção agrícola (D'Silva, 2006, p. 29-34). No caso particular dos pesticidas, entre 1966 e 1979, a Índia aumentou a sua produção doméstica de pesticidas de 50000 toneladas para 65000 (D'Silva, 2006).

Foi neste contexto que se tomou a decisão da instalação, em Bhopal, de uma fábrica que permitisse a produção de carbaril, um pesticida da família dos carbamatos, patenteado pela UCC, vendido comercialmente como Sevin. A fábrica começou a sua atividade em 1969. No momento inicial, o plano era que a fábrica se limitasse a diluir os compostos vindos da fábrica produtora, situada nos Estados Unidos da América (EUA), com ingredientes inertes locais. No entanto, por razões económicas, foi posteriormente definido que a fábrica de Bhopal deveria produzir o carbaril localmente, misturando isocianato de metila (MIC) com alfa-naftol (a pro- 
dução local de MIC iniciou-se em 1980). A fábrica foi instalada na zona norte de Bhopal, a $3 \mathrm{~km}$ do hospital Hamidia e a 1,5 km da estação ferroviária de Bhopal. A fábrica foi instalada numa zona densamente ocupada por construções precárias, definindo-se um anel habitacional em torno do perímetro fabril que, inclusive, foi sendo crescentemente povoado ao longo dos anos de funcionamento. Nestas casas, viviam setores profundamente desfavorecidos e marginalizados da sociedade, trabalhadores do mercado informal (mas também da própria fábrica e ferroviários), muçulmanos e hindus de baixa casta.

Após a meia-noite do dia 3 de dezembro de 1984, uma reação num dos tanques (E-610) onde se reservava o MIC provocou a libertação de uma nuvem de gases tóxicos que, levada pelo vento, se espalhou nas áreas circundantes. As populações das zonas afetadas, sentindo no ar algo parecido com pimenta, e que provocava ardor nos olhos e uma enorme dificuldade em respirar, começaram a correr em pânico, procurando salvar-se da nuvem invisível de gás, procurando chegar ao hospital, num cenário convulso com gente semidespida acabada de acordar, em que familiares se iam chamando e perdendo no meio da confusão. O dia 3 de dezembro amanheceu com um cenário apocalíptico de pessoas temporariamente cegas, vomitando, tossindo, em agonia para respirar, com uma imensidão de corpos de pessoas e animais a serem pisados pelas ruas, e de gente em busca de tratamento junto ao hospital Hamidia, lado a lado com as pilhas de cadáveres que ali se iam acumulando a cada hora.

Na noite do desastre, Gangaram vivia a poucas centenas de metros da fábrica, junto à Oriya Basti Colony. Conta assim a memórias da noite do desastre:

Por volta da meia-noite e meia, estávamos a dormir em casa. Nessa altura, ouvimos um som e toda a gente começou a gritar: "Corram! Corram!". Saímos de casa e já não voltámos para dentro. Éramos quatro na família: eu, a minha mulher e 
os nossos dois filhos. Nós não conseguíamos ver bem. Toda a gente saiu de suas casas, toda a comunidade. Do outro lado da linha férrea existia um barracão do caminho-de-ferro, uma área ampla, e toda a gente estava a correr para lá e nós também fomos. E, quando chegámos à linha férrea, vimos 9 familiares que não estavam mortos, mas desmaiados. Entrámos e vimos os outros, as famílias que também estavam desmaiadas. Então o meu filho disse-me: "Pai, corre porque eu não me estou a sentir bem!" Então fomos para Bhairpur $^{6}$ (entrevista pessoal [EP]).

Gangaram caminhou para Bhairpur juntamente com a família e um vizinho. Pelo caminho encontrou água que usou para lavar os olhos da esposa que tinha ficado cega. Ao chegar a Bhairpur diz ter encontrado cerca de 2000 famílias que fugiam igualmente dos gases. Entre as pessoas que ali estavam fugidas, não se registaram mortes, a queixa mais premente eram as dores nos olhos e a incapacidade de ver. Nessa noite, nasceram duas crianças no meio do caos. Quase ninguém conseguia ver. Ainda no dia 3, apareceu pessoal médico com a polícia, pedindo a todos que fossem para Bhopal, para o hospital, mas o receio de voltar falou mais alto. A cegueira foi paulatinamente dando lugar a visão enevoada e, no dia 4, a polícia voltou dizendo que era seguro voltar para Bhopal. Ao regressar, Gangaram dirigiu-se ao hospital onde recebeu gotas para os olhos. Assim me descreveu o cenário com que se deparou no regresso a Bhopal:

Toda a gente estava morta. Após algumas horas... a 4 de dezembro. Vimos na altura, as plantas não tinham folhas, os frutos estavam rebentados. $E$, à medida que continuávamos, víamos à esquerda e à direita cadáveres, as pessoas a andar sobre cadáveres por todo o lado. Fiquei perturbado. Não havia ninguém para recolher os cadáveres, milhares de cadáveres. Gatos, cães, pessoas, gado por todo o lado. [...] Até que os militares começaram a levar os cadáveres de camião para o hospital Hamidia. Não se sabia se eram hindus ou muçulmanos (EP).

\footnotetext{
${ }^{6}$ Localidade situada a cerca de $16 \mathrm{~km}$ de Bhopal.
} 
No hospital Hamidia, alguns dos corpos que iam sendo recolhidos foram identificados pelas famílias de modo a receberem as devidas exéquias, de acordo com os preceitos religiosos respectivos: cremados se hindus, enterrados se muçulmanos. No entanto, e como referiu Gangaram, além de toda a consternação, a confusão criada e a indistinção entre muçulmanos e hindus ${ }^{7}$ implicou ainda que muitos corpos tivessem recebido exéquias desadequadas às da sua religião, ou seja, muitos muçulmanos foram cremados e hindus enterrados.

A exposição ao gás levaria a que a esposa de Gangaram, grávida de 6 meses na altura do desastre, tivesse um aborto espontâneo. Para a família de Gangaram, essa foi apenas mais uma consequência do desastre. Para Gangaram, persistem as memórias traumáticas do pânico e mortandade que testemunhou, além de problemas de saúde crónicos, mormente problemas respiratórios, que afetam a sua família. ${ }^{8}$ Após o desastre, Gangaram regressou para a sua habitação nas cercanias da fábrica. Como quase todos os afetados pelo desastre, Gangaram continuou a viver junto à fábrica da UCIL, numa zona fortemente afetada pelo desastre. Ficou por falta de alternativa, mas também por uma pertença forte à comunidade

O horror e o caos de que Gangaram me deu conta, foram-me sendo diferentemente descritos por todos os sobreviventes que, na noite do desastre, tinham idade suficiente para os guardar na memória. O confronto com sucessivos testemunhos de perda e resiliência, quase invariavelmente arrancados a memórias difíceis de revisitar, a lágrimas inadvertidas, e a

\footnotetext{
${ }_{7}^{7}$ Neste particular a indistinção é mais forte nos homens, já que a roupa das mulheres, sobretudo os saris hindus, permite frequentemente saber que religião professam.

${ }^{8} \mathrm{O}$ legado da fábrica de pesticidas deixou na população afetada pelo gás um quadro de doenças crónicas permanentes onde pontificam os problemas pulmonares, oftalmológicos, ginecológicos, mentais, dores musculares e de cabeça. Um retrato testemunhado diariamente pelos médicos da clínica da ST e que se encontra confirmado por estudos clínicos (cf. p. ex. Eckerman, 2005, p. 107-117; Cullinan et al., 1996).
} 
silêncios não partilháveis, apenas sublinha o imenso magma de dor que jaz nas histórias de tantos habitantes de Bhopal, mormente as famílias mais pobres, aquelas que ainda habitam as favelas em torno de uma fábrica de pesticidas em ruínas.

Noor Jahan era uma menina quando se mudou com os pais e avós para Bhopal, mais exatamente para a Jai Prakach Nagar Colony, uma das áreas residenciais que, pela proximidade da fábrica e pela direção do vento (de Noroeste para Sudeste), foi mais afetada pela nuvem de gás. Na madrugada de 3 de dezembro, Noor, com 12 anos, acordou com os gritos do tio anunciando que havia um incêndio na fábrica, até que se espalhou a notícia de que havia uma fuga de gás. Foi então que a família de Noor tentou fugir:

As pessoas foram para a beira da estrada e viram o fumo da fábrica, algumas diziam: "isto é nevoeiro". Também diziam que tinha havido uma explosão no contentor de gás. Começou tudo a fugir de camião ou noutros veículos; mas nós não tínhamos nenhum veículo, então ficámos ali duas horas. Após duas horas, o meu tio disse que deveríamos sair dali e levar todos os membros da família. Eu agarrei na filha do meu tio - ela tinha um ano e meio. O meu tio, a minha tia e eu fugimos, caminhámos uns 3-4 quilómetros quando o meu tio se lembrou que se tinha esquecido de fechar a casa. Então voltámos e ficámos a dormir debaixo dos cobertores (EP).

Com alguma fortuna, ao voltarem para casa, Noor e os tios acabaram por adotar uma das estratégias com que se poderiam ter protegido do gás: ${ }^{9}$ ficar em casa tentando isolar a circulação de ar do exterior, apli-

\footnotetext{
${ }^{9}$ Um guião de emergência que teria minimizado os danos do desastre teria em conta as seguintes medidas: um alarme de aviso, o uso de tecidos molhados para cobrir a cara, a permanência em casa sempre que a estrutura permitisse o isolamento do exterior, a opção de caminhar em vez de correr, e a escolha de um percurso que permitisse evitar seguir na direção do vento (Eckerman, 2005, p. 103).
} 
cando, se possível, toalhas molhadas sobre os rostos. No entanto, o pânico e a total desinformação em relação ao perigo levou a que a resposta esmagadora das populações fosse sair de casa, muitas vezes correndo, o que potenciava a aspiração da nuvem de gases tóxicos, onde pontificava o MIC. A família de Noor, tal como muita gente que vivia na vizinhança da fábrica, nem sequer fazia ideia de que esta se destinava à produção de pesticidas muitos simplesmente ignoravam ou julgavam que se tratava de uma fábrica de baterias, produto pelo qual a UCIL era conhecida na Índia.

No entanto, a fuga de Noor continuou. Quando o tio acordou, a família dirigiu-se à plataforma junto à ferrovia, onde muitas pessoas estavam reunidas, sentindo-se ali mais seguras. Mas, quando os tios procuraram sair dali, Noor anunciou que não conseguia ir a lado nenhum, acabando por ser achada na carga de um camião que transportava cadáveres:

Disse à minha tia que não queria ir, porque estava incapaz de respirar, e as pessoas estavam incapazes de respirar. Disse à minha tia: "não vou a lado nenhum, vou ficar aqui e vou morrer aqui. [...] Não conseguia respirar e o meu corpo não se estava a aguentar, então caí para a ferrovia. Eu tinha caído e a polícia municipal estava a recolher os cadáveres. Não sei porque o faziam, talvez os estivessem a recolher para levar para o hospital ou para os atirarem para algum lado. Então recolheram-me e colocaram-me no camião, mas o marido da minha irmã reconheceu-me e disse: "ela é da nossa família". Foi então que me tiraram dali e me levaram ao hospital onde me deram injeções e comprimidos (EP).

Como no caso de Noor, não são infrequentes as histórias de pessoas que acordaram vivas sob cadáveres que estavam a ser preparados para cremação ou enterro, expressão do caos instalado. Noor só encontrou os pais e os irmãos 10 dias depois, quando já os julgava mortos e estes já a julgavam morta. Muitas foram as famílias que jamais se reencontraram. A indemnização que Noor recebe, 200 rupias mensalmente, diz-me, não é suficiente para cobrir idas ao médico e, sempre que pode, tenta juntar al- 
gum dinheiro para ir ao médico privado onde pode encontrar um atendimento mais dedicado. Além dos problemas de saúde que a acompanham e que lhe debilitam fortemente a capacidade de trabalho, explica o estigma que recai sobre as populações que se sabe afetadas pelo gás. Conforme me explicou e pude dar conta em muitos outros testemunhos, esta menorização social percebe-se crucialmente aquando do casamento:

Eu casei-me dois anos e meio após o desastre, mas é uma situação difícil. As pessoas de fora não querem casar com pessoas afetadas pelo gás. A verdade é que eu tive problemas, porque, dois anos após o meu casamento, o meu filho teve doenças de pele. As pessoas normais pensam que, se casarem com uma mulher ou um homem de uma família afetada pelo gás, os seus filhos também vão ser afetados pelo gás (EP).

É, pois, muito frequente que as pessoas afetadas pelo gás acabem por desposar indivíduos em igual circunstância. Numa sociedade em que a escolha de noivo tem uma forte dimensão de compromisso familiar, marcado pela casta e pelo estatuto socioeconómico, as pessoas afetadas pelo gás estão cingidas a uma espécie de endogamia, numa generalizada desconfiança de que o gás que se instalou nos seus corpos possa ser passado às gerações seguintes.

Quando me ia despedir, antes de desligar o gravador, Noor, reparando que me tinha esquecido de perguntar pelo destino dos seus companheiros de fuga na noite do desastre, chamou-me e disse-me:

A menina do meu tio morreu um mês depois do desastre; o meu tio morreu após três anos; e a minha tia morreu também três anos após o desastre - os três morreram. E o meu outro tio também morreu, em poucos anos, por causa da situação das doenças (EP).

Como podemos perceber, o impacto imediato do desastre nas famílias foi muito variável, dependendo sobretudo da área de residência 
e das estratégias de proteção adotadas perante perigo de contornos e implicações desconhecidas. Poucas famílias, no entanto, terão sido tão afetadas como a de Sanjay Verma. Nascido em 1984, Sanjay não tem memórias pessoais do desastre, mas conheceu as suas implicações através da irmã e do irmão mais velhos (respetivamente, 9 e 19 anos, aquando do desastre) e pelo seu envolvimento como ativista dos sobreviventes: "Depois daquela noite, o meu irmão Sunil, a minha irmã Mamta e eu fomos os únicos três sobreviventes. Três irmãs, dois irmãos e os meus pais morreram naquela noite." Sanjay sobreviveu graças à irmã, que lhe haveria de contar a história anos depois:

A minha irmã envolveu-me no cobertor, uma vez que eu era um bebé. O meu irmão e a minha irmã correram juntos - eu ia ao colo da minha irmã. Depois, o meu irmão teve que urinar $[. .]$, foi quando se separaram. Mas, ainda assim, de algum modo, a minha irmã sobreviveu e, uma vez que me tinha nos braços, eu também sobrevivi e acabámos por encontrar o meu irmão na manhã seguinte ou assim (EP).

Tanto quanto o impacto da noite do desastre, a história de Sanjay é instrutiva das sequelas do desastre. O fato de Sanjay não ter memórias da família que perdeu permitiu-lhe ter uma infância relativamente feliz no orfanato onde viveu com a irmã. O mesmo não aconteceu ao irmão de Sanjay, Sunil. Se, por um lado, Sunil canalizou a revolta pelo acontecido para se tornar um dos mais importantes ativistas nos anos subsequentes ao desastre, acabaria por soçobrar à dor, com sérias perturbações psicológicas, muito comuns entre os sobreviventes (BMA \& BGIA, 2012, p. 121), que o levariam a suicidar-se em 2006. Conforme me disse, foi no luto pela morte do seu irmão que Sanjay pôde estabelecer, enfim, um conhecimento mais aproximado do impacto subjetivo do desastre nos sobreviventes. Trata-se de um "saber" imposto pelo confronto com a morte de entes próximos no contexto de um desastre coletivo, um dado da expe- 
riência que, conforme pude perceber pelas entrevistas que recolhi, perpassa esmagadoramente pelos que sobreviveram àquela noite. Foi nesse momento que Sanjay compreendeu o quanto de dor tiveram de carregar os seus dois irmãos que, no dia 4 de dezembro de 1984, acordaram para a perda de sete membros da família nuclear.

O contato com testemunhos do desastre de Bhopal, recolhidos mais de trinta anos depois, mostra, por um lado, como as memórias são sempre profundamente individuais. Trata-se de experiências recapituladas, a partir de uma pletora de afetos e traumas que pertencem à singularidade de cada percurso biográfico. A isto acresce o forte peso das doenças, dores crónicas e deficiências que desproporcionadamente afetam os sobreviventes de Bhopal, algo que nos remete seja para a centralidade do corpo vivido na experiência (Merleau-Ponty, 1999; Csordas, 1990), seja para a incomunicabilidade suscitada pela dor física e pela angústia existencial de um corpo vulnerabilizado (Martins, 2006; Das, 1997). Por outro lado, estas narrativas carregadas de histórias dolorosas e potencialmente disruptivas levam a que a sua evocação, assim pude perceber na marcação e no rescaldo das entrevistas, obedeça a óbvios cuidados de autopreservação: a avaliação da prontidão emocional para um exercício memorativo difícil; a escolha da audiência respeitosa e empática, e a ponderação sobre a bondade do destino das histórias contadas.

Analisando o desastre do Bhopal, Veena Das (1995, p. 138 - 174) analisa como a experiência das vítimas foi mobilizada para discursos profissionais - da administração burocrática, da medicina, do direito - de tal modo que a dor e o sofrimento são tendencialmente elididos em narrativas de legitimação da ordem social e das instituições modernas. Assim, mais do que uma análise imersa nas teodiceias que Max Weber e que na sua esteira - Clifford Geertz (1973) pertinentemente analisaram para sublinhar o papel das cosmologias religiosas na explicação do sofrimento 
e da dissolução do sentido da vida, a leitura ao rescaldo do desastre de Bhopal não pode ser separada de uma perspectiva crítica em relação aos mecanismos pelos quais os sujeitos e as comunidades violentados pelo desastre têm de resistir aos mecanismos que os procuram reinscrever como "corpos dóceis": Nós temos de examinar os mecanismos pelos quais a fabricação da dor, por um lado, e das teologias do sofrimento, por outro, se convertem em formas de legitimar a ordem social e menos em ameaças a essa mesma ordem (Das, 1995, p. 138).

Veena Das considera que o desastre de Bhopal, tendo sido entendido, desde o início, como um evento coletivo e, portanto, claramente apartado da força das leituras rigidamente individuais do sofrimento, teve como sequela a negação das dimensões subjetivas e intersubjetivas da dor. Tal fenómeno deveu-se, a seu ver, ao poder multinacional da indústria de químicos, à escassez de recursos dos grupos de vítimas e à aplicação de lógicas burocráticas na definição de doença, em processos que fizeram do sofrimento um discurso, um tropo verbal, que acabou dissolvendo a realidade existencial dos sobreviventes (Das, 1995, p. 138 -174).

Ao mesmo tempo que são individuais, as memórias de Bhopal, como pude perceber, estão profundamente dependentes, senão de uma memória coletiva, de histórias partilhadas que reescrevem o passado ao mesmo tempo que inscrevem os sujeitos nos sucessivos presentes de onde falam. Kyrmayer refere com argúcia que

[o] trauma partilhado por uma comunidade inteira cria um espaço público potencial para reenunciação. Se uma comunidade concorda que os eventos traumáticos aconteceram e incorpora este fato na sua identidade, então a memória coletiva sobrevive e a memória individual pode encontrar um lugar (ainda que transformado) dentro dessa paisagem (Kirmayer, 1996, 189-190).

No entanto, o contexto de Bhopal e as enunciações que pude recolher têm menos que ver com a validação da experiência individual ou 
com a criação de espaços de enunciação - importantes como são - do que com uma declarada luta por justiça e por uma vida melhor. Esta dimensão é particularmente forte em Bhopal, face a uma situação de injustiça e precariedade que, após 1984, tem sido ostensiva e incessantemente reproduzida, e que nos remete para o que muitas organizações locais designam como "o segundo desastre de Bhopal".

\section{Os sujeitos da "violência lenta"}

O elenco dos eventos e das decisões que culminaram no desastre de 3 de dezembro de 1984 revela um olímpico descaso pelas vidas das populações que habitavam as favelas do Norte da cidade de Bhopal.

Em primeiro lugar, está a própria decisão de instalar uma fábrica de pesticidas numa zona que já era densamente povoada, sem que, ao longo dos anos, alguma medida tenha sido tomada para impedir novas construções nas zonas circunvizinhas, ou para levar a cabo um plano de segurança que passaria pela elementar informação das populações sobre os perigos a que estavam sujeitos, e por um plano de evacuação.

Em segundo lugar, porque a tecnologia usada para a produção de carbaril em Bhopal assentava em tecnologia não comprovada: devido à eventual não adaptação às especificidades do solo e do clima locais; pela adoção de um método de reação mais barato, mas que comportava riscos acrescidos; pelas restrições existentes à importação de tecnologia ao abrigo de legislação protecionista indiana; e por um generalizado improviso e facilitismo que levaram ao uso de tecnologia obsoleta, estabelecendo um abismo entre as tecnologias e padrões de segurança usados em Bhopal e na sua congénere nos EUA. ${ }^{10}$

\footnotetext{
${ }^{10}$ Ingrid Eckerman $(2005$, p. 28-29) oferece um exaustivo inventário das deficiências de tecnologia e planeamento da fábrica de Bhopal.
} 
Em terceiro lugar, porque houve um acentuado desinvestimento, com sérias implicações de segurança, à medida que a rentabilidade da fábrica de Bhopal foi sendo posta em causa. O esforço para maximizar os lucros, primeiro, e para reduzir os prejuízos a partir de 1981, terá decorrido de vários fatores: das dificuldades técnicas para produzir o alfa-naftol localmente, projeto nunca realizado, o efeito negativo de anos de seca na procura de pesticidas; e a introdução na Índia de novos pesticidas, mais eficazes e mais baratos do que o carbaril (D'Silva, 2006, p. 66, 67). A situação levou a que, em 1984, ano do desastre, estivesse a ser seriamente equacionado o desmantelamento da fábrica para ser reinstalada em unidades separadas na Indonésia e no Brasil (ibidem, p. 88). Os sucessivos cortes no funcionamento e nos funcionários levaram a que operações sensíveis fossem executadas por pessoal sem experiência, que cessassem operações de manutenção e reparação e a que fossem cortados custos em áreas tão cruciais. Para que tenhamos uma ideia mais exata do impacto destes cortes, convém frisar que a refrigeração dos tanques que armazenavam o MIC (onde se iniciou a reação que desencadearia o desastre), cuja função era prevenir reações endotérmicas, encontrava-se desligada (2006, p. 90). Do mesmo modo, a torre de queima de gás, a que caberia destruir os gases de uma eventual fuga de MIC, estava inoperacional na noite do acidente (ibidem).

O modo como as vidas dos habitantes de Bhopal foram desconsideradas no itinerário que tornou possível o desastre de Bhopal dá conta de um processo meticuloso de subalternização, que consente na reiteração da categoria de sub-humano. Esta categoria sedimenta-se, a nível local, pelo modo como a destituição económica e cultural dos habitantes das favelas é congruente com classificações racistas e religiosas, num país em que os muçulmanos e hindus de baixa casta se encontram entre os mais excluídos. De uma perspectiva mais vasta, pelo fato de a Índia pertencer, 
ainda, a um espaço marcado pelas lógicas de desigualdade planetária do sistema-mundo, forjadas na divisão entre colónias e metrópoles. A Índia pertenceu ao espaço colonial, exterioridade não europeia ainda cristalizada na sensibilidade do Ocidente através da permanência do nexo colonial-racista que nasceu com a expansão europeia oceânica, a partir do final século XV (Bethencourt, 2013). As colónias, mais exatamente os territórios outrora coloniais, nesse sentido, correspondem ao que a sensibilidade anti-colonial de Frantz Fanon designou por "zonas de não ser" (Fanon, 1967). Nestas demarcações de humanidade, denota-se, como refere Boaventura de Sousa Santos, que a concepção ocidental, capitalista e colonialista da humanidade não é pensável sem o conceito de sub-humanidade (Santos; Chaui, 2013).

Se tivermos em conta as irrisórias compensações financeiras, as insuficientes estruturas para atender às necessidades médicas, e a poluição que ainda marca a envolvência da área em que se situava a fábrica da UCC/ UCIL (BMA \& BGIA, 2012; Elliot, 2014), podemos dizer que as três décadas que se seguiram ao desastre exprimem, singularmente, o descaso a que tem estado votada a população marcada pelo impacto do desastre de Bhopal. As vidas perdidas em Bhopal, bem como as dos sobreviventes, emergem, assim, como representações proverbiais das vidas não passíveis de luto:

As vidas não passíveis de luto são aquelas que não podem ser perdidas, e que não podem ser destruídas. Porque habitam uma zona perdida e destruída; elas são, ontologicamente, desde o início, perdidas e destruídas (Butler, 2010, p xix).

Assim se explica que, após o desastre, nenhuma comoção pelos mortos ou reconhecimento do sofrimento instaurado às vidas achadas entre os despojos do desastre tenha mobilizado um efetivo ânimo de justiça, fosse da parte do Estado Indiano, da UCC, dos EUA, ou das instituições internacionais. As tribulações que se seguiram ao desastre são expressivas disso mesmo. 
Em primeiro lugar, a luta por compensações por parte dos sobreviventes de Bhopal esbarrou num acordo estabelecido, sob os auspícios do Supremo Tribunal da Índia, entre o governo indiano e a UCC. Segundo este acordo, a UCC pagou 470 milhões ao governo indiano, que recebeu o montante em nome das vítimas - sem que estas tenham alguma vez sido consultadas. Com o acordo, foram dados como nulos quaisquer outros processos cíveis ou criminais contra a UCC/UCIL. Face aos danos já conhecidos, o acordo estabeleceu uma verba insignificante que permitiu à UCC continuar a sua atividade económica sem danos de maior. $\mathrm{O}$ governo Indiano redistribuiu o dinheiro às vítimas de tal modo que cerca de 94\% das vítimas receberam menos de 500 dólares, que foram sendo pagos ao longo dos anos em prestações mensais de 200 rupias. Uma quantia, conforme pude perceber, manifestamente insuficiente para fazer face aos mais elementares problemas de saúde que afetam os sobreviventes. Ao optar por um acordo tão desfavorável, fica claro que a principal preocupação do governo indiano foi a de não hostilizar o investimento internacional. Boaventura de Sousa Santos refere que os Estados operam segundo três estratégias: acumulação, hegemonia e confiança (2000, p. 279). Nesse sentido, perante o acordo estabelecido, parece lícito concluir que o Estado indiano claramente privilegiou o princípio da acumulação, em detrimento da confiança dos cidadãos que alegou representar.

Em segundo lugar, as responsabilidades criminais apuradas foram-no tardia e escassamente, revelando um quadro de impunidade. Em 1991, respondendo a um recurso, o Supremo Tribunal Indiano revogou a cessação das acusações criminais estabelecidas. No entanto, o CEO da UCC, Warren Anderson (falecido em 2014) nunca compareceu na Índia para responder por homicídio culposo, e o pedido de extradição, só emitido em 2003, foi sempre recusado pelos EUA. Em 2010, oito altos funcionários indianos da filial indiana da UCC (UCCIL) foram acusados com multas 
e penas de prisão de até dois anos, sentenças que geraram a indignação pública pela sua insignificância em face do desastre.

Em terceiro lugar, desde o dia do desastre, a área da fábrica e a envolvente permanecem fortemente contaminadas. Em particular, o solo e as águas subterrâneas que ao longo das últimas décadas serviam para o consumo das populações das áreas envolventes contêm elevados níveis de toxicidade. Isto mesmo ficou comprovado por um estudo da Greenpeace em 1999:

De modo geral, a pesquisa conduzida pela Greenpeace International demonstrou uma grave contaminação do solo e da água das reservas de água de consumo com metais pesados e contaminantes orgânicos persistentes tanto dentro como na envolvência da antiga fábrica de produção de pesticidas da UCIL (Greenpeace, 1999, p. 4).

Perante este quadro, a exigência da limpeza da área contaminada (que inclui reservas de compostos que continuam perigosamente armazenadas na antiga área de produção dos pesticidas) estabeleceu-se como uma etapa crucial das reivindicações de ativistas e sobreviventes (BMA \& BGIA, 2012, p. 136, 137). Em 2001, a UCC foi adquirida pela Dow Chemical, passando a ser a esta empresa que cabem as responsabilidades pendentes da UCC. Apesar dos continuados apelos dos ativistas de Bhopal, até hoje a Dow Chemichal continua a recusar-se a assumir a limpeza da área contaminada.

Vitimados por um desastre continuado, que se apôs ao desastre de 1984, os sobreviventes de Bhopal encontram-se perante um quadro profundamente marcado por doenças crónicas debilitantes da qualidade de vida e da aptidão para o trabalho, recebendo compensações que nem Ihes conferem os recursos adequados para receberem cuidados médicos condignos. Por outro lado, sem que alguma vez tenham visto alguém ser responsabilizado pela magnitude do desastre que se interpôs nas suas 
vidas, as novas gerações estão sofrendo com malformações genéticas e doenças que resultam do consumo de água contaminada.

A oportunidade de tomar contato com a comunidade afetada pelo desastre, mais de 30 anos depois, colocou-me perante a força descritiva daquilo a que Rob Nixon designa por "violência lenta"11 (Nixon, 2009; 2011) e que entende como a violência que ocorre gradualmente e longe da vista, uma violência da destruição diferida que está dispersa pelo tempo e pelo espaço, uma violência de atrito que normalmente nem sequer é entendida como violência (Nixon, 2011, p. 2).

Trata-se, pois, de uma forma de violência que escapa às apreensões correntes e que reclama por uma renovada sensibilidade crítica:

A violência é habitualmente entendida como uma ação que é imediata no tempo, explosiva e espetacular no espaço, e que eclode com uma visibilidade instantânea. Precisamos, creio, de nos ocuparmos de um tipo diferente de violência, a violência que não é espetacular nem instantânea, mas gradual e cumulativa, cujas repercussões calamitosas se movem através de uma série de escalas temporais (Nixon, 2011, p. 2).

De fato, tanto o caráter insidioso da violência lenta como a invisibilidade potenciada pelos regimes hierárquicos que se concertam na desqualificação social daqueles que foram e são as vítimas de Bhopal concorrem para um quadro em que, como se pôde perceber, os "direitos do poder" se sobrepõem ao "poder dos direitos" (Falk, 2009, p. 25). Esta conclusão, sendo expressiva de uma pujante assimetria de poder que tende a perpetuar as condições de desamparo dos sobreviventes, fracassa em valorizar as conquistas e ensinamentos produzidos pelas histórias de luta de insurgência. É nesse sentido que me parece importante pensar as histórias de Bhopal na perspectiva das "epistemologias do Sul" (Santos, 2014).

\footnotetext{
${ }^{11}$ Não é uma casualidade que o desastre de Bhopal, por via do romance de Indra Sinha, Animal's People, tenha sido um dos casos a partir do qual Rob Nixon aprofundou e materializou o conceito de "violência lenta".
} 


\section{As "epistemologias do Sul": resistências e aprendizagens}

Numa reflexão que se vem sedimentando em estreita articulação com os conceitos de "sociologia das ausências", "sociologia das emergências", "ecologia dos saberes" (Santos, 2002) e "tradução intercultural" (Santos, 2014, p. 238), Boaventura de Sousa Santos define as epistemologias do Sul como o conjunto de procedimentos dirigidos à validação de conhecimentos nascidos na luta, de formas de saber desenvolvidas por grupos sociais como parte da sua resistência contra as injustiças sistémicas causadas pelo colonialismo, pelo capitalismo e pelo patriarcado (2014, p. x).

De fato, a partir de uma perspectiva atenta às resistências que se engendraram a partir do desastre de Bhopal, é também possível entrever um fôlego contraparadigmático com que os poderes do colonialismo, ${ }^{12}$ do capitalismo e do patriarcado foram sendo combatidos pelos sobreviventes. Sem recursos ou influência política, a história da luta dos sobreviventes de Bhopal merece ser assinalada, e pode ser dividida em três formas de ação centrais. Em primeiro lugar, as manifestações públicas. Estas têm consistido em manifestações de rua, marchas, greves de fome, vigílias, seja para colocar na agenda reivindicações específicas ou para contestar decisões dos governantes ou dos tribunais, seja ainda para assinalar o dia do desastre de Bhopal ou outras datas relevantes. Neste particular, cabe salientar as importantes padyartas - longas marchas de protesto a pé - de importância e visibilidade crucial na história da luta. A primeira padyarta aconteceu em 1989 e foi decisiva para encetar uma cultura de resistência: 75 mulheres acompanhadas de 30 crianças (seus filhos), caminharam mais de $700 \mathrm{~km}$, para reunir com o primeiro-ministro, em Nova Deli. A segunda padyarta aconteceu em 2008, também de Bhopal para Deli.

\footnotetext{
${ }^{12}$ Aqui entendido como legado colonial, num sentido próximo ao de "colonialidade do poder" (Quijano, 2000) ou de "formações imperiais" (Stoler, 2008).
} 
Cabe ainda salientar o jejum levado a cabo em novembro de 2014, em Delhi, por 5 mulheres sobreviventes.

Uma segunda dimensão da resistência tem sido o uso da lei, dos tribunais e do escrutínio da documentação política. Seja interpondo processos e recursos ou usando as prerrogativas do direito à informação, o ativismo de Bhopal tem tido uma atividade frenética, explorando todas as possibilidades emancipatórias do Direito e exercendo um apertado escrutínio das decisões políticas a diferentes escalas. A capacidade de intervenção das organizações de Bhopal, além da dedicação dos sobreviventes, tem sido crucialmente beneficiária da presença de ativistas idos de lugares e quadros biográficos mais privilegiados, que têm emprestado o seu capital académico e social à causa de Bhopal. ${ }^{13}$

Finalmente, cabe salientar a ação solidária de ONG que se mobilizam para prestar serviços aos sobreviventes. Neste particular, é de destacar o papel da ST e do Chingari Rehabilitation Centre, um centro de reabilitação que garante ensino e reabilitação aos filhos dos sobreviventes que nasceram com malformações genéticas e outras deficiências. Ambas as organizações se situam próximo da fábrica devoluta e fazem visitas ambulatórias às comunidades.

Esta ação concertada, além de permitir atenuar muitas das condições desesperadas que afetam os sobreviventes e suas famílias, tem tido um papel decisivo nalgumas medidas que travaram a injustiça estrutural que recai sobre as vítimas de Bhopal. Cabe destacar algumas conquistas: a revogação, em 1991, do impedimento de processos criminais contra responsáveis da UCC/UCIL; a expedição do pedido de extradição de

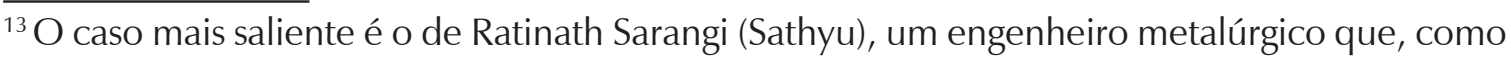
muitos voluntários, acorreu a Bhopal nos dias seguintes ao desastre. De tal modo abraçou a luta dos sobreviventes que, em função dela, vive em Bhopal desde 1984. É trustee da ST e dirigente do Bhopal Group for Information and Action.
} 
Warren Anderson; a realização de estudos que permitiram aferir do impacto do desastre na saúde e na poluição ambiental; a ordem do supremo tribunal, em 2004, para que fosse providenciada às populações água não contaminada (resolução só cumprida em 2014, depois de muita insistência); a distribuição às vítimas, a partir de 2010, das taxas de juro relativas à indemnização paga em 1989 pela UCC; e a aceitação pelo governo, em novembro de 2014, da revisão das categorias médicas que estiveram na atribuição das compensações subavaliadas.

A luta dos sobreviventes de Bhopal foi igualmente instrumental para a criação de um imenso espírito de solidariedade entre as comunidades afetadas, fato bem percetível, por exemplo, no modo como a identidade de sobrevivente, criando uma mesma luta, esvazia quaisquer divisões que pudessem existir, ainda que exteriormente potenciadas, entre hindus e muçulmanos.

Cabe ainda destacar o protagonismo que as mulheres assumiram, desde a primeira hora, enquanto protagonistas da luta pelos direitos dos sobreviventes. Tal protagonismo tem longa história, desde a primeira padyarta, em 1989, exclusivamente formada por mulheres. ${ }^{14}$ Champa Devi Shukla (uma sobrevivente que hoje ocupa as funções de trustee do Chingari Rehabilitation Centre) explica as razões desse protagonismo:

[Nós, mulheres] tivemos que sair de casa, de ganhar dinheiro para as nossas famílias, mas ao mesmo tempo tínhamos de lidar com todo o sofrimento da família, o que provocava imensa raiva, porque nada daquilo era culpa nossa. Costumávamos ir ver os deficientes físicos e mentais, e os bebés que nasciam mortos, fazia parte do apoio dado às vitimas. A minha neta nasceu com uma deficiência, uma fenda palatar. [...] Sim, todas fomos vítimas do desastre de gás. Vi o meu marido sofrer, os meus filhos a sofrer. Depois de ver todo

\footnotetext{
${ }^{14}$ Sobre a relevância das mulheres nos primeiros anos da luta dos sobreviventes ver Kim Fortun (2001, 217250)
} 
Sociologias, Porto Alegre, ano 18, no 43, set/dez 2016, p. 116-148

este sofrimento, tive de trabalhar para cuidar de todos os meus familiares. Sofrimento, é isto que sentimos. Ainda o ano passado perdi um filho, que deixou um filho e uma fiIha. Por isso, sinto que tenho de ultrapassar todas as minhas tristezas e ter força para lutar pela vida dos meus netos e da minha nora (EP).

Conforme pude perceber ao longo do trabalho de campo, a resposta de Champa Devi Shukla reflete duas dimensões cruciais para a centralidade adquirida pelas mulheres no ativismo dos sobreviventes. Em primeiro lugar, está o papel que as mulheres ocupam como custódia do bem-estar da família. Expressão disso mesmo são as histórias de Noor Johan e de Mamta, irmã de Sanjay, contadas atrás. Elas dão conta de um detalhe muito significativo, presente igualmente noutras narrativas: na noite do desastre, quase invariavelmente, são as mulheres que carregam as crianças. Este papel social das mulheres, que naquele como noutros contextos marcadamente nutre o cuidado da família (Shiva, 1988), faz com que as mulheres emerjam, nos anos a seguir ao desastre, enquanto representantes do sofrimento que não é apenas o delas: é o sofrimento dos filhos e das filhas, dos maridos e daqueles que morreram. Por outro lado, o desastre transformou o papel tradicional das mulheres fazendo-as assumir um maior protagonismo na vida pública. Se, até ao desastre, era frequente que muitas das mulheres, sobretudo as muçulmanas, se limitassem a trabalhar em casa (tanto no trabalho doméstico como a enrolar beedis ${ }^{15}$ para fora), depois dele, deram-se transformações assinaláveis. Houve, portanto, uma restruturação social a partir da desestruturação trazida pelo desastre. Nessa nova lógica, as mulheres tiveram que assumir um papel complementar ou substitutivo da remuneração dos maridos, tiveram ainda que comparecer nos espaços de intervenção e protesto como

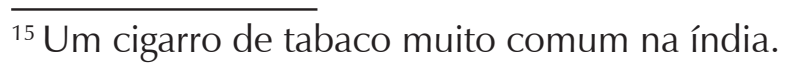


forma de ativamente aplacarem as dificuldades vividas a nível pessoal e familiar. Nesta medida, a luta das sobreviventes de Bhopal, além de anticolonial, antirracista e anticapitalista, carrega, também, uma interessante narrativa feminista.

Aprender com a memória de outros lugares, cujas tribulações são menos conhecidas, confere a possibilidade de reconstituição de uma memória social que se não dobre às fronteiras do humano ou às linhas de fronteira, que outrora definiram como exploráveis os espaços coloniais. Essas memórias são vitais ensinamentos, também na medida em que seja possível reconhecer que, muitas vezes de modo crucial, a memória não está no nível da representação, mas a nível de um gesto particular com o qual você habita o mundo (Das, 2010).

\section{Conclusão}

Tanto quanto desprovincializar a narração da modernidade (Chakrabarty, 2000), fazer viajar histórias de resistência, nascidas de situações tão desesperadas como a de Bhopal, pode ser, ironicamente, uma forma de fazer viajar a esperança dos lugares onde ela é ainda, às vezes, tão desesperada. A memória da injustiça e da violência - longamente inscrita nos corpos e nos testemunhos - é crucial para que se edifique a necessidade de alternativas ao modo como a modernidade produziu categorias de humano e sub-humano. A luta pela sobrevivência da memória não é separável da luta dos sobreviventes que, no presente, inventam gramáticas de dignidade e reconhecimento.

Acredito que, mais de trinta anos depois, as vidas e as vozes dos sobreviventes de Bhopal podem oferecer temporalidades emancipatórias. Em primeiro lugar, na medida em que estas vozes se interpõem ante a "monocultura do tempo linear" (Santos, 2002, 247). Falo do modo com as suas narrativas 
se opõem à celebração de um progresso inevitável, bem representado, por exemplo, pela ideologia modernista na base da "revolução verde"16, ou pelo necessário clima de inimputabilidade empresarial mantido para que o capital internacional, tido como o motor do futuro, se não iniba.

Em segundo lugar, essas vozes exaltam-se para colocar na memória coletiva um desastre que, apesar de fulminante e espetacular, aconteceu numa parte do mundo em que o tempo do esquecimento sobre o sofrimento humano tende a correr mais veloz. A atualidade de um desastre acontecido há mais de 30 anos na Índia como que permite calibrar a lonjura do tempo, sincronizando a memória do desastre humano, nas diferentes latitudes.

Em terceiro lugar, as vozes de Bhopal reinventam o tempo ao trazerem a violência lenta para uma linguagem passível de ser apreendida pela velocidade da informação mediática. Falo dos protestos públicos, ponderosamente afeitos a serem representados pela mídia, ora porque convocam a superação ou o aniquilamento do ser, como os jejuns ou as padyartas, ou porque criam, através das manifestações e comemorações, realidades mais cinemáticas e fotogénicas do que a realidade dos seus sofrimentos, lentos, interiores e invisíveis.

Recrutando para os usos do tempo aquilo que Boaventura de Sousa Santos define como pensamento abissal (2014, p. 118-135), creio ser possível dizer que as vidas de Bhopal, naquilo que têm de emancipatório e contra-hegemónico, comportam a força de uma memória pós-abissal. A memória pós-abissal, defendo, é aquela que identifica a memória abissal enquanto um segundo fôlego da violência colonial. Uma memória pós-abissal da violência terá que ser capaz de conter as vastas latitudes da

\footnotetext{
${ }^{16} \mathrm{~A}$ revolulção verde na Índia e a sua estreita relação com o desesate de Bhopal espelha bem como, crescentemente, as sociedades se têm confrontado com os riscos produzidos através da ação humana, ideia celebremente sintetizada naquilo que Ulrick Beck designou de sociedade de risco (1992).
} 
experiência moderna, os vastos suis, carregando corpos e violências, mortos e sobreviventes, reconhecendo, como promessa de novos saberes, o tempo testemunhado por aqueles que melhor conheceram os escombros da modernidade.

Bruno Sena Martins é Doutor em Sociologia pela Universidade de Coimbra. Atualmente é pesquisador do Centro de Estudos Sociais (CES) da Universidade de Coimbra. $\$ bsenamartins@ces.uc.pt

\section{Referências}

1. BAXI, U. From Human Rights to the right to be Human: Some heresies. India International Centre Quarterly, v. 13, n. 3/4, p. 185-200, 1986.

2. BECK, U. The Risk Society. Towards a New Modernity. London: Sage, 1992.

3. BETHENCOURT, F. Racisms: from the Crusades to the Twentieth Century. Princeton, NJ: Princeton University Press, 2013.

4. BMA \& BGIA. The Bhopal Marathon. Brighton: Bhopal Medical Appeal, 2012.

5. BUTLER, J. Undoing Gender. New York: Routledge, 2004a.

6. BUTLER, J. Precarious life: the powers of mourning and violence. London: Verso, 2004b.

7. BUTLER, J. Frames of war: when is life grievable? London: Verso, 2010.

8. CHAKRABARTY, D. Provincializing Europe: postcolonial thought and historical difference. Princeton, NJ: Princeton University Press, 2000.

9. CSORDAS, T. Embodiment as a Paradigm for Anthropology. Ethos, v. 18, n. 1, p. 5-47, 1990.

10. CULLINAN, P. et al. Long term morbidity in survivors of the 1984 Bhopal gas leak. The National Medical Journal of India, v. 9, n. 1, p. 5-10, 1996.

11. DAS, V. Critical events: An anthropological perspective on contemporary India. Delhi; New York: Oxford University Press, 1995

12. DAS, V. Language and Body: Transactions in the Construction of Pain. In: Arthur Kleinman; Veena Das et al (orgs.). Social Suffering. Berkeley: University of California Press, 1997. 
13. DAS, V; DIFRUSCIA, T. Listening to Voices: An interview with Veena Das. Altérités, v. 7, n. 1, p. 136-145, 2010.

14. D'SILVA, T. The Black Box of Bhopal: A Closer Look at the World's Deadliest Industrial Disaster. Victoria, BC: Trafford, 2006.

15. ELLIOTT, J. India: After 30 Years, Bhopal Is Still Simmering. Newsweek, 12 de janeiro, 2014.

16. ECKERMAN, I. The Bhopal saga: causes and consequences of the world's largest industrial disaster. Hyderabad: Universities Press, 2005.

17. FALK, R. Achieving human rights. New York: Routledge, 2009.

18. FANON, F. The wretched of the earth. New York: Grove Press, 2004.

19. FANON, F. Black Skin, White Masks. New York: Grove Press, 1967.

20. FORTUN, K. Advocacy after Bhopal: environmentalism, disaster, new global orders. Chicago: University of Chicago Press, 2001.

21. GEERTZ, C. The interpretation of cultures: selected essays. New York: Basic Books, 1973.

22. GREENPEACE. The Bhopal Legacy. 1999. Disponível em: <http://www. greenpeace.org/international/Global/international/planet-2/report/1999/10/thebhopal-legacy-toxic-cont.pdf>. Acesso em: 1 de out. 2014.

23. KIRMAYER, L. Landscapes of memory: trauma, narrative, and dissociation. In: ANTZE, P.; LAMBEK, M. (orgs.). Tense past: cultural essays in trauma and memory. New York: Routledge, 1996.

24. KLEINMAN, A. Pain and Resistance: the Delegitimation and Relegitimation of Local Worlds. In: GOOD, M-J. et al (orgs). Pain as Human Experience: an Anthropological Perspective. Berkeley: University of California Press, 1992.

25. MARTINS, B. S. E se eu fosse cego: narrativas silenciadas da deficiência. Porto: Afrontamento, 2006.

26. MERLEAU-PONTY, M. Fenomenologia da Percepção. São Paulo: Martins Fontes, 1999.

27. NIXON, R. Neoliberalism, slow violence, and the environmental picaresque. Modern Fiction Studies, v. 55, n. 3, p. 443-467, 2009.

28. NIXON, R. Slow violence and the environmentalism of the poor. Cambridge, MA: Harvard University Press, 2011.

29. OLIVER-SMITH, A. Anthropological Research on Hazards and Disasters. Annual Review of Anthropology, v. 25, p. 303-328, 1996. 
30. QUIJANO, A. Colonialidad del poder y clasificación social. Journal of WorldSystems Research, v. 6, n. 2 p. 342-386, 2000.

31. SANTOS, B. de S. Crítica da Razão Indolente: Contra o Desperdício da Experiência. Porto: Afrontamento, 2000.

32. SANTOS, B. de S. Para uma Sociologia das Ausências e uma Sociologia das Emergências. Revista Crítica de Ciências Sociais, n. 63, p. 237-280, 2002.

33. SANTOS, B. de S.; CHAUI, M. Direitos Humanos, Democracia e Desenvolvimento. São Paulo: Cortez, 2013.

34. SANTOS, B. de S. Epistemologies of the South: Justice Against Epistemicide. Boulder: Paradigm Publishers, 2014.

35. SHIVA, V. Staying alive: women, ecology, and development. London: Zed Books, 1988.

36. STOLER, A. L. Imperial Debris: Reflections on ruins and ruination. Cultural Anthropology, v. 23, n. 2, p. 191-219, 2008.

Recebido: 12.01.2016

Aceite: 10.05.2016 